\title{
Periocular Anthropometry of Normal Chinese and Indian Populations in Singapore
}

\author{
Pattaraorn Yu, Parvathi Nathan and Chou Siaw Meng* \\ School of Mechanical and Aerospace Engineering, Nanyang Technological University, Singapore
}

Submission: March 28, 2019; Published: May 15, 2019

*Corresponding author: Chou Siaw Meng, School of Mechanical and Aerospace Engineering, Nanyang Technological University, 50 Nanyang Avenue, 639798, Singapore

\begin{abstract}
The purpose of this study is to establish normative eyelid anthropometry of Chinese and Indian adults in Singapore. This is a cross-sectional study where the ocular region of 150 Chinese participants (85 males and 65 females) between 18-40 years and 70 Indian participants (40 males and 30 females) between 20- 33 years were measured for Palpebral Fissure Length (PFL) and Height (PFH), Eyebrow Height (UELB), Interpupillary Distance (IPD), Intercanthal Distance (ICD), palpebral fissure area (PFA), visible iris area (VIA), total iris area (TIA), PFH/PFL and VIA/PFA ratio. The variation in the eyelid anthropometry of the participants was analyzed by the Student's t-test. The PFL, PFH, IPD and PFH/ PFL values differed $(p<0.05)$ between genders of both races. The ICD value was different only in Indian participants whereas the PFA and VIA/ PFA values depicted variation only in Chinese. The PFL, PFH, PFA, VIA and TIA values were greater in Indian eyes whereas the UELB, ICD and VIA/PFA values were greater in Chinese. The gender differences included the rounder eye fissure in women and the wider distance between the pupils in men of both populations. The racial differences of both genders included the comparatively bigger eye and iris area in the Indian population, whereas, the Chinese had comparatively greater left-to-right medial canthus and eye-to-eyebrow distances and higher percentage of iris coverage.
\end{abstract}

Keywords: Periocular; Eyelid Anthropometric Norms; Chinese; Indian; Anthropometry

\section{Introduction}

Periocular anthropometry is valuable in several clinical assessments including the evaluation of pathology and congenital deformities, the study of normal craniofacial development, traumatology, forensic identification and reconstructive operation [1]. Without anthropometric guideline, the post-operative outcome may be unsatisfying and even give rise to the illusory impression of ocular hypertelorism [2]. This challenge, therefore, emphasizes the need in accurate orbital anthropometric measurements.

There are many published reports on periocular anthropometric studies on various ethnic groups including White [3-6], Indian [6-8], Indian American [4], Brazilian [9], Iranian [10], Korean [11-13], Italian [14], Chinese [5,6,13,15,16], Nigerian [17] and Malay [18]. Most of the previous studies reported only a few selected linear measurements such as Palpebral Fissure Length (PFL), Palpebral Fissure Height (PFH) and Intercanthal Width (ICD). The lack of the complete anthropometric data of the periocular area including linear measurements, area measurements and ratios which is important for evaluation of the overall impression has necessitated such dataset in clinical assessment. It is well-known that appearance of the human face is influenced by age, gender and ethnicity [3] and thus anthropometric normative data should be specifically collected according to these factors. Although periocular anthropometric measurements are typically standardized by considering those factors, this study focused on young adult aged more than 18 years and middle-aged adults aged less than 40 years in which individual has fully grown and not yet deteriorated by age [11]. Our ethnic groups of interest are Chinese and Indian which are the world's first and second largest populations [19] and the first and third most dominant populations in Singapore [20]. The aim of this study was to establish a comprehensive normative dataset of periocular anthropometric measurements for Chinese and Indian young adults residing in Singapore.

\section{Materials and Methods}

The study was conducted on 150 Chinese adults in the age group of 18 to 30 years (85 males and 65 females) and 70 Indian adults between the ages of 20 and 33 years ( 40 males and 30 females). No subject had a history of periocular pathology, oculoplastic surgery, orbital trauma, facial injuries, or facial reconstructive operation. This study was approved by the Institutional Review Board of Nanyang Technological University (IRB no: IRB-2015-05-035). 
All subjects were photographed in the frontal view with a Canon G2 Power shot digital camera in a well-lit room. A transparent ruler was placed on the forehead slightly above the eyebrow on the same plane as the eye to allow accurate calibration. To minimize the photographic distortion, subjects were asked to maintain their head straight and eyes wide open without any facial expression. The camera should be aligned to the axial plane of the eye and the image should be no left-to-right rotation. Only the photographs in which the subject's faces were clearly at rest were used to ensure the facial features were not distorted due to any voluntary or involuntary facial movement.

The periocular measurement method used in this study was 2D photography which was found to be valid and used in many studies $[7,9,12,21,22]$. The acquired images were analyzed by the National Institutes of Health (NIH) Image J software. The software allows measurements by calibrating the image pixel to the ruler, thus providing the computed linear and area measurements in $\mathrm{mm}$ and $\mathrm{mm}^{2}$, respectively.
The following linear measurements (Figure 1) were measured by the software:

a) Palpebral fissure length (PFL): the distance from the inner commissure between the sclera and soft tissue (endocanthion) to the outer commissure between the sclera and soft tissue (exocanthion);

b) Palpebral Fissure Height (PFH): the distance between the upper and lower eyelid margin of a naturally open eye;

c) Distance between the open Upper Eyelid Margin and the Lower Eyebrow Margin (UELB): The perpendicular distance between the highest point of the open upper eyelid and the lower eyebrow margin;

d) Intercanthal distance (ICD): the distance between the medial canthi of both eyes;

e) Interpupillary distance (IPD): the distance between the pupils of both eyes

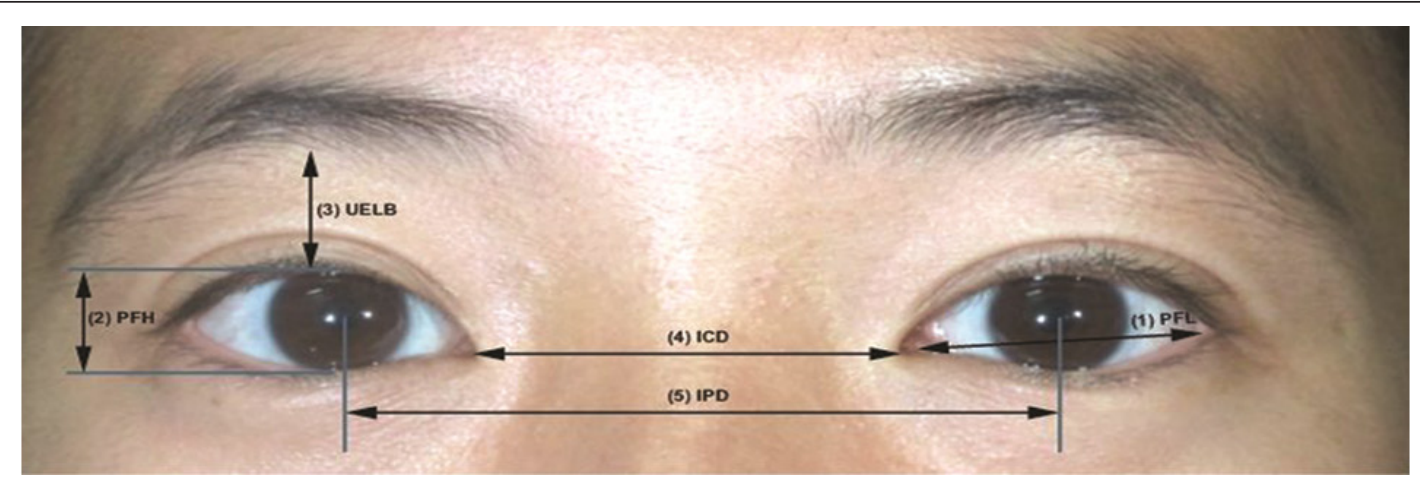

Figure 1: Periocular linear measurements. 1, Palpebral fissure length (PFL); 2, Palpebral fissure height (PFH); 3, Upper eyelid to lower eyebrow distance (UELB); 4, Intercanthal distance (ICD); 5, Interpupillary distance (IPD).

The area measurements included the enclosed area of palpebral fissure (PFA), visible iris (VIA) and total iris (TIA). The palpebral fissure height-length ratio (PFH/PFL) and the ratio of the visible iris area and palpebral fissure area (VIA/PFA) were also computed. Mean and standard deviation of the measured values were calculated for statistical analysis. The Student's $t$-test was performed whereby differences among genders and races were considered statistically significant when $p$-value is less than 0.05. The comparison was done between Chinese male
(CM) vs Chinese female (CF), Indian male (IM) vs Indian female (IF), Chinese male (CM) vs Indian male (IM) and Chinese female (CF) vs Indian female (IF).

\section{Results}

The anthropometric periocular measurements and p-values of Chinese and Indian young adults residing in Singapore are presented in Table 1. Table 2 shows group comparison between genders and races.

Table 1: Periocular Measurements and statistical difference of Chinese and Indian populations $(n=220)$.

\begin{tabular}{|c|c|c|c|c|c|c|c|c|c|c|c|}
\hline \multirow[b]{2}{*}{ Measurements } & \multirow[b]{2}{*}{ Gender } & \multicolumn{3}{|c|}{ Chinese } & \multicolumn{3}{|c|}{ Indian } & \multicolumn{4}{|c|}{ p-value } \\
\hline & & $\begin{array}{c}\text { Mean } \\
\text { (SD) }\end{array}$ & Min & Max & $\begin{array}{c}\text { Mean } \\
\text { (SD) }\end{array}$ & Min & $\operatorname{Max}$ & $\mathrm{CM}$ vs $\mathrm{CF}$ & IM vs IF & CM vs IM & CF vs IF \\
\hline \multirow{2}{*}{ PFL (mm) } & Male & $23.9(2.1)$ & 18.2 & 28 & $29.1(2.5)$ & 23.9 & 35 & $0.026^{*}$ & $0.003^{*}$ & $\mathrm{p} \leq 0.001^{*}$ & $\mathrm{p} \leq 0.001^{*}$ \\
\hline & Female & $23.2(1.7)$ & 19.9 & 27.4 & $27.4(2.3)$ & 22.8 & 30.7 & & & & \\
\hline \multirow{2}{*}{ PFH (mm) } & Male & $8.4(1.6)$ & 3.3 & 11.4 & $10.0(1.6)$ & 7.2 & 14.3 & $\mathrm{p} \leq 0.001^{*}$ & $\mathrm{p} \leq 0.001^{*}$ & $\mathrm{p} \leq 0.001^{*}$ & $\mathrm{p} \leq 0.001^{*}$ \\
\hline & Female & $9.7(1.5)$ & 6.1 & 12.8 & $11.2(1.1)$ & 9.1 & 13.7 & & & & \\
\hline
\end{tabular}




\begin{tabular}{|c|c|c|c|c|c|c|c|c|c|c|c|}
\hline \multirow{2}{*}{ UELB (mm) } & Male & $10.6(2.6)$ & 5.5 & 21.6 & $7.2(2.6)$ & 1.4 & 12.6 & 0.939 & 0.393 & $\mathrm{p} \leq 0.001^{*}$ & $\mathrm{p} \leq 0.001^{*}$ \\
\hline & Female & $10.5(2.4)$ & 5 & 15.9 & $7.7(2.2)$ & 3.8 & 13 & & & & \\
\hline \multirow{2}{*}{$\operatorname{ICD}(\mathrm{mm})$} & Male & $35.4(3.0)$ & 29.3 & 44.5 & $32.0(3.0)$ & 25.2 & 39.7 & 0.292 & $0.038^{*}$ & $\mathrm{p} \leq 0.001^{*}$ & $\mathrm{p} \leq 0.001^{*}$ \\
\hline & Female & 34.9 (2.9) & 29.9 & 41.9 & $30.4(3.1)$ & 24.9 & 38.2 & & & & \\
\hline \multirow{2}{*}{ IPD (mm) } & Male & $61.9(3.5)$ & 53.5 & 72.2 & $62.7(5.2)$ & 51.2 & 76.9 & $\mathrm{p} \leq 0.001^{*}$ & $\mathrm{p} \leq 0.001^{*}$ & 0.067 & 0.37 \\
\hline & Female & $59.2(3.5)$ & 51.6 & 68.7 & $57.6(4.1)$ & 51.5 & 65.4 & & & & \\
\hline \multirow{2}{*}{ PFA (mm2) } & Male & $\begin{array}{l}141.8 \\
(35.2)\end{array}$ & 57 & 211.5 & $\begin{array}{l}188.0 \\
(45.3)\end{array}$ & 111.7 & 327.9 & $0.048^{*}$ & 0.138 & $\mathrm{p} \leq 0.001^{*}$ & $\mathrm{p} \leq 0.001^{*}$ \\
\hline & Female & $\begin{array}{l}152.1 \\
(28.5) \\
\end{array}$ & 77.4 & 206 & $\begin{array}{l}201.0 \\
(26.9)\end{array}$ & 151.8 & 259.6 & & & & \\
\hline \multirow{2}{*}{ VIA (mm2) } & Male & $\begin{array}{c}71.5 \\
(15.9) \\
\end{array}$ & 30.3 & 109 & $\begin{array}{c}83.0 \\
(13.1) \\
\end{array}$ & 57 & 113.5 & 0.859 & 0.193 & $\mathrm{p} \leq 0.001^{*}$ & $\mathrm{p} \leq 0.001^{*}$ \\
\hline & Female & $\begin{array}{c}71.9 \\
(13.4) \\
\end{array}$ & 47.9 & 106.8 & $\begin{array}{c}87.8 \\
(16.2) \\
\end{array}$ & 63.3 & 135.4 & & & & \\
\hline \multirow{2}{*}{ TIA (mm2) } & Male & $\begin{array}{c}91.3 \\
(14.6) \\
\end{array}$ & 57.1 & 116 & $\begin{array}{c}113.2 \\
(20.0) \\
\end{array}$ & 82.2 & 165.6 & 0.782 & 0.529 & $\mathrm{p} \leq 0.001^{*}$ & $\mathrm{p} \leq 0.001^{*}$ \\
\hline & Female & $\begin{array}{c}90.6 \\
(14.8)\end{array}$ & 63.4 & 129.8 & $\begin{array}{c}110.0 \\
(20.9)\end{array}$ & 67.2 & 159.5 & & & & \\
\hline \multirow{2}{*}{ PFH/PFL (\%) } & Male & $34.9(5.9)$ & 17.3 & 45.7 & $34.3(5.4)$ & 23 & 45.4 & $\mathrm{p} \leq 0.001^{*}$ & $\mathrm{p} \leq 0.001^{*}$ & 0.505 & 0.59 \\
\hline & Female & $41.7(6.0)$ & 27.1 & 56.7 & $41.0(3.3)$ & 36.2 & 49.5 & & & & \\
\hline \multirow{2}{*}{ VIA/PFA (\%) } & Male & $51.3(7.6)$ & 37.9 & 80.1 & $45.3(7.1)$ & 31.9 & 66.3 & $0.008^{*}$ & 0.386 & $0.010^{*}$ & $\mathrm{p} \leq 0.001^{*}$ \\
\hline & Female & $47.9(7.5)$ & 30.6 & 67 & $43.9(6.6)$ & 31.5 & 54.7 & & & & \\
\hline
\end{tabular}

$\mathrm{CM}$, Chinese male; CF, Chinese female; IM, Indian male; IF, Indian female, * Significant difference.

Table 2: Comparison between genders and races $(n=220)$.

\begin{tabular}{|c|c|c|c|c|c|c|c|c|}
\hline & \multicolumn{3}{|c|}{ Comparison between Male and Female } & \multicolumn{3}{c|}{ Comparison between Chinese and Indian } \\
\hline & \multicolumn{2}{|c|}{ CM vs CF } & \multicolumn{2}{c|}{ IM vs IF } & \multicolumn{2}{c|}{ CM vs IM } & \multicolumn{2}{c|}{ CF vs IF } \\
\hline & Comparison & $p$-value & Comparison & $p$-value & Comparison & $p$-value & Comparison & $p$-value \\
\hline PFL & $>$ & $0.027^{*}$ & $>$ & $0.003^{*}$ & $<$ & $\mathrm{p} \leq 0.001^{*}$ & $<\leq 0.001^{*}$ \\
\hline PFH & $<$ & $\mathrm{p} \leq 0.001^{*}$ & $<$ & $\mathrm{p} \leq 0.001^{*}$ & $<$ & $\mathrm{p} \leq 0.001^{*}$ & $<$ & $\mathrm{p} \leq 0.001^{*}$ \\
\hline UELB & NS & 0.939 & $\mathrm{NS}$ & 0.393 & $>$ & $\mathrm{p} \leq 0.001^{*}$ & $>$ & $\mathrm{p} \leq 0.001^{*}$ \\
\hline ICD & NS & 0.292 & $>$ & $0.038^{*}$ & $>$ & $\mathrm{p} \leq 0.001^{*}$ & $>$ & $\mathrm{p} \leq 0.001^{*}$ \\
\hline IPD & $>$ & $\mathrm{p} \leq 0.001^{*}$ & $>$ & $\mathrm{p} \leq 0.001^{*}$ & $\mathrm{NS}$ & 0.067 & $\mathrm{NS}$ & 0.37 \\
\hline PFA & $<$ & $0.048^{*}$ & NS & 0.138 & $<$ & $\mathrm{p} \leq 0.001^{*}$ & $<$ & $\mathrm{p} \leq 0.001^{*}$ \\
\hline VIA & NS & 0.856 & NS & 0.193 & $<$ & $\mathrm{p} \leq 0.001^{*}$ & $<$ & $\mathrm{p} \leq 0.001^{*}$ \\
\hline TIA & NS & 0.77 & NS & 0.529 & $<$ & $\mathrm{p} \leq 0.001^{*}$ & $<$ & $\mathrm{p} \leq 0.001^{*}$ \\
\hline PFH/PFL & $<$ & $\mathrm{p} \leq 0.001^{*}$ & $<$ & $\mathrm{p} \leq 0.001^{*}$ & $\mathrm{NS}$ & 0.505 & $\mathrm{~N}$ & 0.59 \\
\hline VIA/PFA & $>$ & $0.008^{*}$ & NS & 0.388 & $>$ & $0.010^{*}$ & $>$ & $\mathrm{p} \leq 0.001^{*}$ \\
\hline
\end{tabular}

$\mathrm{CM}$, Chinese male; CF, Chinese female; IM, Indian male; IF, Indian female, *Significant difference, NS = non-significant.

The result of the comparison is reported as the former group was greater (>) than the latter group, and vice versa.

In comparison between genders ( $\mathrm{CM}$ vs $\mathrm{CF}$ and IM vs IF; see the first and second columns of Table 2), seven out of ten values of both races exhibited the same trend. The PFL, PFH, IPD and $\mathrm{PFH} / \mathrm{PFL}$ values differed significantly $(\mathrm{p}<0.05)$ among genders in both races: the PFL and IPD values were greater in males but the PFH and PFH/PFL values were lesser. The UELB, VIA and TIA values were not significantly different between males and females of both races. However, the ICD value was significantly greater only in Indian subjects while the PFA and VIA/PFA values were significantly lower and higher respectively in Chinese. 
In comparison between races (CM vs IM and CF vs IF; see the third and fourth columns of Table 2), all values of both races exhibited the same trend. All values differed significantly among races of both genders $(\mathrm{p}<0.05)$ except the IPD and PFH/PFL values which showed no significant difference. The PFL, PFH, PFA, VIA and TIA values were significantly greater in Indian eyes but the UELB, ICD and VIA/PFA values were significantly greater in Chinese.

\section{Discussion}

Chinese and Indian are the top two largest populations of the world [19] and the first and third biggest populations in Singapore [20]. Malay, as the second largest population in Singapore [20], was notincluded in this study due to the similarity of its anthropological origin to Chinese as Mongoloids [18]. To date, the most completed periocular anthropometric reports of various racial groups were done by Farkas et al. [1,6] However, the studies focused on the horizontal linear measurements but the vertical linear measurements (e.g., palpebral fissure height), area measurements and ratios were not included. By considering linear measurements, area measurements and ratios, some interesting characteristics were revealed as discussed below.

In both races (see the first and second columns of Table 2), the smaller PFL and greater PFH in women showed that women had rounder eyes, where men had slightly wider and significantly vertically narrower eyes (almond shape). This observation agrees with the PFH/PFL value which was higher in women of both races. It is also interesting to note that, even though women had smaller PFL and greater PFH, the eye area or PFA between men and women of both races were generally the same (PFA of $\mathrm{CM}$ vs $\mathrm{CF}$ showed $\mathrm{p}=0.048$ ). On comparing between races, Indian eyes had greater PFH and PFL than Chinese eyes (see the third and fourth columns of Table 2). However, the PFH/PFL value of Indian and Chinese eyes had no significant difference ( $p>0.05)$ in both genders. In the other words, Chinese and Indian women, who had rounder eyes than their male counterparts, had similar $\mathrm{PFH} / \mathrm{PFL}$ values which were significantly greater than those of Chinese and Indian men. The eye roundness characteristic of women was also observed in other races including Korean [11,12], Indian [3], Malaysian Indian [8], Chinese [3,15,23], African American [23], and North American Caucasian [23]. Those studies also reported that women had smaller PFL and greater PFH than men. This finding suggests that the rounder palpebral fissure might be one of the feminine attributes.

Another characteristic observed only between genders was the greater IPD in men. It showed that the centres of the male pupils were located further apart from the face midline than those of women. However, when considering the greater PFL in men, the ratio of the distances from the medial canthus to the pupil and from the pupil to the lateral canthus of both men and women might be similar. Hence, the greater IPD value did not imply that the location of the pupils was unnaturally nearer to the lateral canthi. Similar observation was reported in Korean [11] and Indian [7].

An obvious distinctive feature between Chinese and Indian was the Indian's larger eye and iris area. The PFL, PFH, PFA, VIA and TIA of Indian subjects were significantly greater $(\mathrm{p}<0.05)$ than Chinese. Despite the bigger eye and iris area in Indian, the VIA/PFA ratio of Chinese was found to be higher. This implied that Chinese eyes had higher percentage of iris coverage than Indian eyes.

Chinese and Indian could also be differentiated by the UELB and ICD. It was found that Chinese eyes had higher eyebrow (greater UELB) and wider distance between left and right medial canthi (greater ICD). An inter-racial study by Kunjur et al. [3] also reported similar results.

The major limitation of this research study is the relatively small sample size and the cross-sectional design. A longitudinal study could enable a deeper understanding and determination of the trend periocular anthropometry of individual participants. The results obtained in this study may not be considered as representative of the total Chinese and Indian population in Singapore owing to the small size and the inclusion of young and middle-aged participants.

\section{Conclusion}

In this study, we reported a comprehensive normative dataset of periocular anthropometric measurements for Chinese and Indian young adults residing in Singapore. It was found that the gender differences included the rounder eye fissure in women and the wider distance between the pupils in men. The racial differences were evident from the bigger eye and iris area in Indians and greater left-to-right medial canthus and eyeto-eyebrow distances and higher percentage of iris coverage in Chinese participants. The anthropometric periocular measurements and p-values of Chinese and Indian young adults residing in Singapore are presented in Table 1. Table 2 shows group comparison between genders and races.

In comparison between genders (CM vs CF and IM vs IF; see the first and second columns of Table 2), seven out of ten values of both races exhibited the same trend. The PFL, PFH, IPD and PFH/PFL values differed significantly $(\mathrm{p}<0.05)$ among genders in both races: the PFL and IPD values were greater in males but the PFH and PFH/PFL values were lesser. The UELB, VIA and TIA values were not significantly different between males and females of both races. However, the ICD value was significantly greater only in Indian subjects while the PFA and VIA/PFA values were significantly lower and higher respectively in Chinese.

In comparison between races (CM vs IM and CF vs IF; see the third and fourth columns of Table 2), all values of both races exhibited the same trend. All values differed significantly among races of both genders $(\mathrm{p}<0.05)$ except the IPD and PFH/PFL values which showed no significant difference. The PFL, PFH, 
PFA, VIA and TIA values were significantly greater in Indian eyes but the UELB, ICD and VIA/PFA values were significantly greater in Chinese.

\section{References}

1. Farkas LG (1994) Anthropometry of the head and face. Journal of Oral and Maxillofacial Surgery 53(6): 733.

2. Cohen Jr MM, Richieri Costa A, Guion Almeida ML, Saavedra D (1995) Hypertelorism: interorbital growth, measurements, and pathogenetic considerations. International Journal of Oral and Maxillofacial Surgery 24(6): 387-395.

3. Kunjur J, Sabesan T, Ilankovan V (2006) Anthropometric analysis of eyebrows and eyelids: an inter-racial study. British Journal of Oral and Maxillofacial Surgery 44(2): 89-93.

4. Husein OF, Sepehr A, Garg R, Sina Khadiv M, Gattu S, et al. (2010) Anthropometric and aesthetic analysis of the Indian American woman's face. J Plast Reconstr Aesthet Surg 63(11): 1825-1831.

5. Lam CS, Loran DF (1991) Designing contact lenses for oriental eyes. Journal of the British Contact Lens Association 14(3): 109-114.

6. Farkas LG, Katic MJ, Forrest CR, Alt KW, Bagic I, et al. (2005) International anthropometric study of facial morphology in various ethnic groups/races. Journal of Craniofacial Surgery 16(4): 615-646.

7. Patil SB, Kale SM, Math M, Khare N, Sumeet J (2011) Anthropometry of the eyelid and palpebral fissure in an Indian population. Aesthetic Surgery Journal 31(3): 290-294.

8. Ngeow W, Aljunid S (2009) Craniofacial anthropometric norms of Malaysian Indians. Indian Journal of Dental Research 20(3): 313-319.

9. Hanada AL, Souza Jr EN, Moribe I, Cruz AAV (2001) Comparison of palpebral fissure obliquity in three different racial groups. Ophthalmic Plastic \& Reconstructive Surgery 17(6): 423-426.

10. Etezad Razavi M, Jalalifar S (2008) Correlation between Interpupillary and Inner-Outer Intercanthal Distances in Individuals Younger than 20. Journal of ophthalmic \& vision research 3(1): 16-22.

11. Park DH, Choi WS, Yoon SH, Song CH (2008) Anthropometry of Asian eyelids by age. Plastic and reconstructive surgery 121(4): 1405-1413.
12. Song W, Kim S, Kim S, Hu K, Kim H, et al. (2007) Asymmetry of the palpebral fissure and upper eyelid crease in Koreans. Journal of plastic, reconstructive \& aesthetic surgery 60(3): 251-255.

13. Cho M, Glavas IP (2009) Anatomic properties of the upper eyelid in Asian Americans. Dermatologic Surgery 35(11): 1736-1740.

14. Sforza C, Grandi G, Catti F, Tommasi DG, Ugolini A, et al. (2009) Age-and sex-related changes in the soft tissues of the orbital region. Forensic science international 185(1): 115.

15. Jayaratne YS, Deutsch CK, Zwahlen RA (2013) Normative Findings for Periocular Anthropometric Measurements among Chinese Young Adults in Hong Kong. BioMed research international.

16. Dawei W, Guozheng Q, Mingli Z, Farkas LG (1997) Differences in horizontal, neoclassical facial canons in Chinese (Han) and North American Caucasian populations. Aesthetic plastic surgery 21(4): 265269.

17. Eze BI, Uche JN, Shiweobi JO, Mba CN (2012) Oculopalpebral Dimensions of Adult Nigerians: Report from the Enugu Normative Ocular Anthropometry Study. Medical Principles and Practice 22(1): 75-79.

18. Ngeow W, Aljunid S (2009) Craniofacial anthropometric norms of Malays. Singapore Dental Journal 50(5): 525-528.

19. (2014) U.S. and World Population Clock: United States Census Bureau.

20. (2013) Population trends: Singapore Department of Statistics.

21. Nunes TP, Oliveira TFd, Matayoshi S (2005) A comparative study of the manual and digital measurements of the palpebral fissure. Arquivos Brasileiros de Oftalmologia 68(6): 785-787.

22. Douglas T, Martinez F, Meintjes E, Vaughan C, Viljoen D (2003) Eye feature extraction for diagnosing the facial phenotype associated with fetal alcohol syndrome. Medical and Biological Engineering and Computing 41(1): 101-106.

23. Hajniš K, Farkas LG, Ngim RC, Lee ST, Venkatadri G (1994) Racial and ethnic morphometric differences in the craniofacial complex. In: Farkas LG. Anthropometry of the head and face. 2A Edition, New York: Raven Press, p. 2.

\section{Your next submission with Juniper Publishers will reach you the below assets}

- Quality Editorial service

- Swift Peer Review

- Reprints availability

- E-prints Service

- Manuscript Podcast for convenient understanding

- Global attainment for your research

- Manuscript accessibility in different formats

( Pdf, E-pub, Full Text, Audio)

- Unceasing customer service

Track the below URL for one-step submission https://juniperpublishers.com/online-submission.php 